Article

\title{
Production, Characterization, and Evaluation of Pellets from Rice Harvest Residues ${ }^{\dagger}$
}

\author{
Cristina Moliner*D, Alberto Lagazzo $\mathbb{D}^{D}$, Barbara Bosio, Rodolfo Botter and Elisabetta Arato $\mathbb{D}$ \\ Dipartimento di Ingegneria Civile, Chimica e Ambientale (DICCA), Università degli Studi di Genova, Via Opera \\ Pia 15A, 16145 Genova, Italy; alberto.lagazzo@unige.it (A.L.); Barbara.bosio@unige.it (B.B.); \\ Rodolfo.botter@unige.it (R.B.); elisabetta.arato@unige.it (E.A.) \\ * Correspondence: cristina.moliner@edu.unige.it \\ † This paper is an extended version of our paper published in 27th European Biomass Conference \& Exhibition \\ (EUBCE 2019), Lisbon, Portugal, 27-30 May 2019; pp. 1023-1028.
}

Received: 20 December 2019; Accepted: 14 January 2020; Published: 18 January 2020

check for updates

\begin{abstract}
Pellets from residues from rice harvest (i.e., straw and husk) were produced and their main properties were evaluated. Firstly, rice straw pellets were produced at lab scale at varying operational conditions (i.e., load compression and wt \% of feeding moisture content) to evaluate their suitability for palletization. Successively, rice straw and husk pellets were commercially produced. All the samples were characterized in terms of their main physical, chemical, and physico-chemical properties. In addition, axial/diametral compression and durability tests were performed to assess their mechanical performance. All the analyzed properties were compared with the established quality standards for non-woody pellets. In general, rice straw pellets presented suitable properties for their use as pelletized fuels. Rice husk pellets fell out of the standards in recommended size or durability and thus preliminary treatments might be required prior their use as fuels.
\end{abstract}

Keywords: rice harvest pellets; palletization; combustion; ash recovery; normative

\section{Introduction}

Rice is one of the most consumed crops worldwide, with an annual production of 700 million tons according to the Food and Agriculture Organization of the United Nations database [1]. The largest producers in Europe are Italy and Spain with an $80 \%$ of the total rice production. Italy (with a total cultivated surface of 220,000 ha) is the largest producer mainly in the Po basin (the Piedmont, Lombardy, Venetia, and the Romagna). The second-largest European rice producer is Spain, with 117,000 ha. Andalucia and Valencia are the main rice-producing regions, the latter harboring a more stable water supply which benefits the production.

The main by-products of rice harvest are rice straw and rice husk which represent an environmental and economic problem for the farmers. Rice straw, for example, is usually eliminated by uncontrolled burning with harmful consequences related to air, flora, and fauna pollution in wetlands. As an alternative, rice waste is abandoned or sunk, being decomposed in fields, causing major die-off of fish and other aquatic fauna in deeper areas [2]. Currently, different European moratoria permitting uncontrolled burning are being applied, since no reliable solutions are being implemented.

In this framework, the EU-funded project LIFE LIBERNITRATE [3] proposes a synergic application of efficient rice waste management to treat nitrate problems in over-cropping areas. This is achieved through the controlled combustion of rice straw and the successive production of silica-based adsorbents from the obtained ashes, which are applied as filters to decrease the high concentration of nitrates in waters. 
Combustion efficiencies are optimized using rice straw in the form of pellets. Raw materials are light and irregular which results in difficulties for their collection, transport, storage, and operation. Bulk density of rice straw and rice husk are around $60 \mathrm{~kg} / \mathrm{m}^{3}$ [4] and $90 \mathrm{~kg} / \mathrm{m}^{3}$ [5], respectively, with recommended pellet values in the range $600-800 \mathrm{~kg} / \mathrm{m}^{3}[6]$.

The quality of pellets depends both on the properties of the feeding and on the operational conditions for its production. For that reason, understanding the physical, chemical, and mechanical properties of the initial feedstock becomes essential to evaluate their behavior during combustion. The control of the moisture content plays an important role: Within the optimal percentage (10-14\%) it serves as binding agent, facilitates heat transfer, and promotes self-bonding of individual particles in the pellet $[7,8]$. However, an increase of this optimal value could decrease inter-particle forces that might cause swelling and disintegration of pellets [9]. Also, the assessment of the applied load compression applied must be careful evaluated: Low void fractions inside the pellet can prevent oxygen diffusion into the inner part restricting the combustion only to the outer surface [10].

On the other hand, the chemical composition of the feedstock provides indications on the potential emissions and operational problems that could occur on the device helping in their prevention. In this sense, special attention has to be paid to sintering and fouling owing to the high content of silica present in rice straw (RS) and rice husk (RH): Their ash analysis show concentrations around $70 \mathrm{mg} / \mathrm{kg}$ and $100 \mathrm{mg} / \mathrm{kg}$ of silica, respectively [11]. This implies increased risks for sintering and dust emissions and a lowering on the heating value [12]. Also, emissions associated with biomass combustion, such as $\mathrm{NO}_{X}$, need to be evaluated [13].

Finally, storage, transport, and processing of pellets can lead to a loss of their mechanical properties. A significant loss on mechanical strength might increase the level of dust and consequently, the risk of fire and explosions as well as being a health hazard for workers [14]. Moreover, high strength values can result in extremely hard pellets causing difficulties during solids feeding due to bridging.

Within this framework, the main physical, chemical, and mechanical properties of single press and commercially produced pellets using rice straw and rice husk were investigated. Their properties were evaluated by comparing them with the standard limits for non-woody pellets and their suitability as combustion feeding materials in the framework of LIFE LIBERNITRATE was discussed.

\section{Materials and Methods}

\subsection{Production of Rice Straw Pellet with a Single Press}

Rice straw was provided by Società Agricola Abbazia ( $\left.45^{\circ} 22^{\prime} 59.34^{\prime \prime} \mathrm{N} 9^{\circ} 58^{\prime} 22.3^{\prime \prime} \mathrm{E}\right)$, Orzinuovi (Brescia, Italy). All tests were performed at the Laboratorio di Ingegneria dei Materiali (DICCA, UNIGE). Rice straw was initially cut to get short fibers and then grounded using a chopper with rotating blades for $1 \mathrm{~min}$ at $4000 \mathrm{rpm}$. Sieves with an aperture of $1 \mathrm{~mm}, 0.85 \mathrm{~mm}, 0.3 \mathrm{~mm}$, and $0.15 \mathrm{~mm}$ were used to obtain the granulometric distribution of the straw powders. The obtained particle size distribution after grinding is presented in Figure 1. A particle size range between 0.5 to $0.7 \mathrm{~mm}$ is suggested in literature [15]. Sizes larger than $1 \mathrm{~mm}$ could act as preferential breaking points. On the contrary, small particles with large surface area could increase density values and lead to tougher pellets. In this work, only the fraction in the range $0.15-1 \mathrm{~mm}$ was used to provide a homogenous sample according to established criteria.

The pellet press consisted of a cylindrical $8 \mathrm{~mm}$ diameter die of steel, a fitted piston, and a hydraulic press. The compression of the material was obtained by pressing, with the hydraulic press, against a fixed backstop. A fixed quantity of $0.25 \mathrm{~g}$ of rice straw was used. A constant force detected by a $150 \mathrm{kN}$ load cell was applied for one minute at room temperature. After compression, the pressure was released, the bottom of the cylinder removed, and the pellet pressed out of the cylinder. For determination of experimental precision, four replicates were carried out. Pellets had in general a cylindrical shape and are about $8 \mathrm{~mm}$ in diameter. 


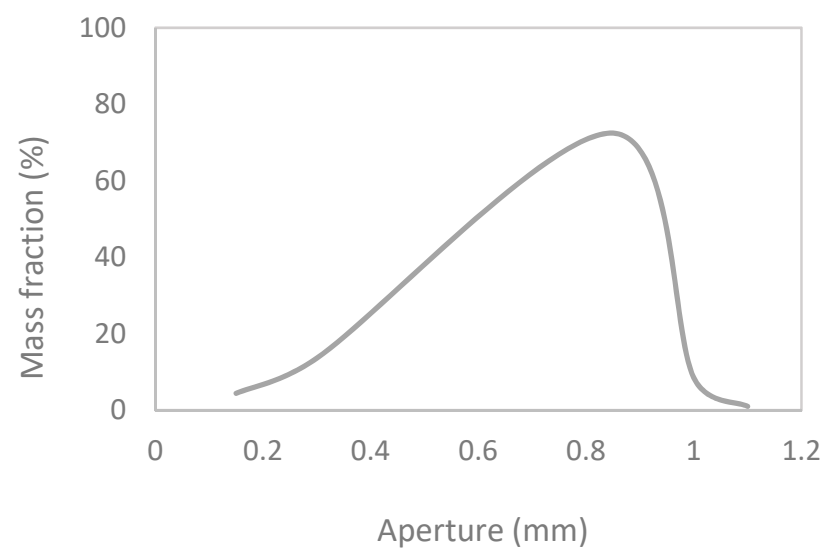

Figure 1. Particle size distribution of grounded rice straw.

Different compression forces (1-10 tons) and amount of added distilled water (40-60 mg) were used. Figure 2 shows examples of the produced pellets.
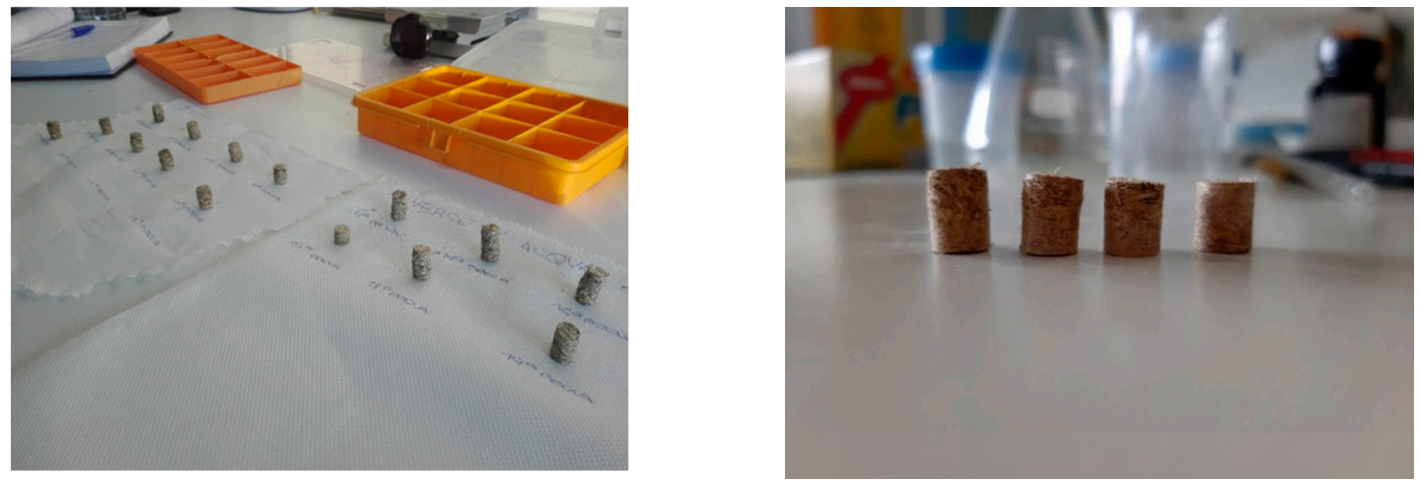

Figure 2. Pellets produced using the single press.

\subsection{Production of Commercial Pellets}

The available $10 \mathrm{~kg}$ of RS and $23 \mathrm{~kg}$ of RH were cut and reduced to a length less than $3-4 \mathrm{~cm}$. This feedstock was sent to a commercial pellet producer, Novapellet (Novara, Italy) [16]. A size refinement was performed to obtain dimensions of $6 \mathrm{~mm}$ by $2 \mathrm{~mm}$ by $1 \mathrm{~mm}$ in order to ensure proper densification. The moisture content of both materials was within the range 10-14\% wt. In accordance to the experimental procedure at lab-scale, no binder was used in the process. Pellets were produced at a temperature range of $60^{\circ} \mathrm{C}$ to $70^{\circ} \mathrm{C}$ with the commercial pelletizer N-PICO (Novapellet) with a maximum capacity of $200 \mathrm{~kg} / \mathrm{h}$ and nominal power of $10 \mathrm{~kW}$ [17]. Figure 3 shows the pelletizer (a) and the pelletized RS (b).

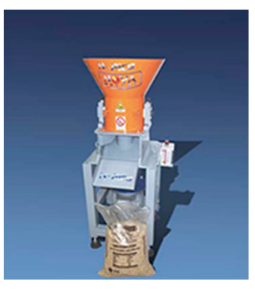

(a)

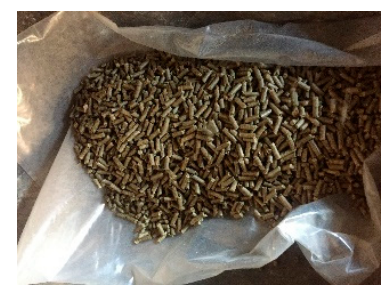

(b)

Figure 3. N-Pico pelletizer (a) and pelletized rice straw (RS) (b). 


\subsection{Characterization of Pellets}

Physical, chemical and mechanical properties of all samples were evaluated at the Laboratorio di Ingegneria dei Materiali (DICCA, UNIGE) and compared with standards [17]. The produced commercial pellets ( $6 \mathrm{~kg}$ of RS and $2 \mathrm{~kg}$ of $\mathrm{RH}$ ) were stored for two weeks before characterization. Firstly, the specimens were sub-divided, and a representative sample was selected. The following characteristics were evaluated.

\subsubsection{Physical Properties}

Twenty randomly chosen pellets were used to determine the length $(L)$ and the diameter $(d)$ of the pellets $(\mathrm{mm})$ using a caliper (precision $1 / 20 \mathrm{~mm}$ ). Particle density $\left(\rho_{p}\right)(\mathrm{UNE}-\mathrm{EN} 15,150)[18]$ was determined by weighing the individual pellet using a precision digital balance and calculating its volume based on the length and diameter previously determined. The pellet shape was assumed to be cylindrical. Bulk density $\left(\rho_{b}\right)$ (UNE-EN 15103) [19] was calculated from the volume and weight of pellets using a laboratory balance and a graduated cylinder. Porosity $\left(\varepsilon_{0}\right)$ was then calculated from particle and bulk density as:

$$
\varepsilon_{0}(-)=1-\frac{\rho_{b}}{\rho_{p}}
$$

\subsubsection{Chemical Properties}

Proximate analysis (PA) was calculated using a muffle furnace following the standards [20-22]. Ultimate analysis (UA) was calculated using a Vario MACRO Cube Elementar Analyzer. The heat release by the unit of mass during the combustion of RS and RH was evaluated through the higher heating value (HHV) using the empirical expression [23]:

$$
H H V(M J / K g)=0.3536 F C+0.1559 V M-0.0078 A
$$

With the fixed carbon (FC), volatiles (VM), and ash (A) content in mass percentage.

\subsubsection{Mechanical Properties}

Axial and diametral compression tests were carried out with a Hausfield universal mechanical tester. The equipment was set at a load cell capacity of $5 \mathrm{kN}$ at a rate of $20 \mathrm{~mm} / \mathrm{min}$ (Figure 4). The corresponding strength values were determined as the minimum force at which pellet broke. That way, the resistance of pellet to deformation and breakage when compressed vertically and horizontally were evaluated which are likely scenarios during transport and storage.

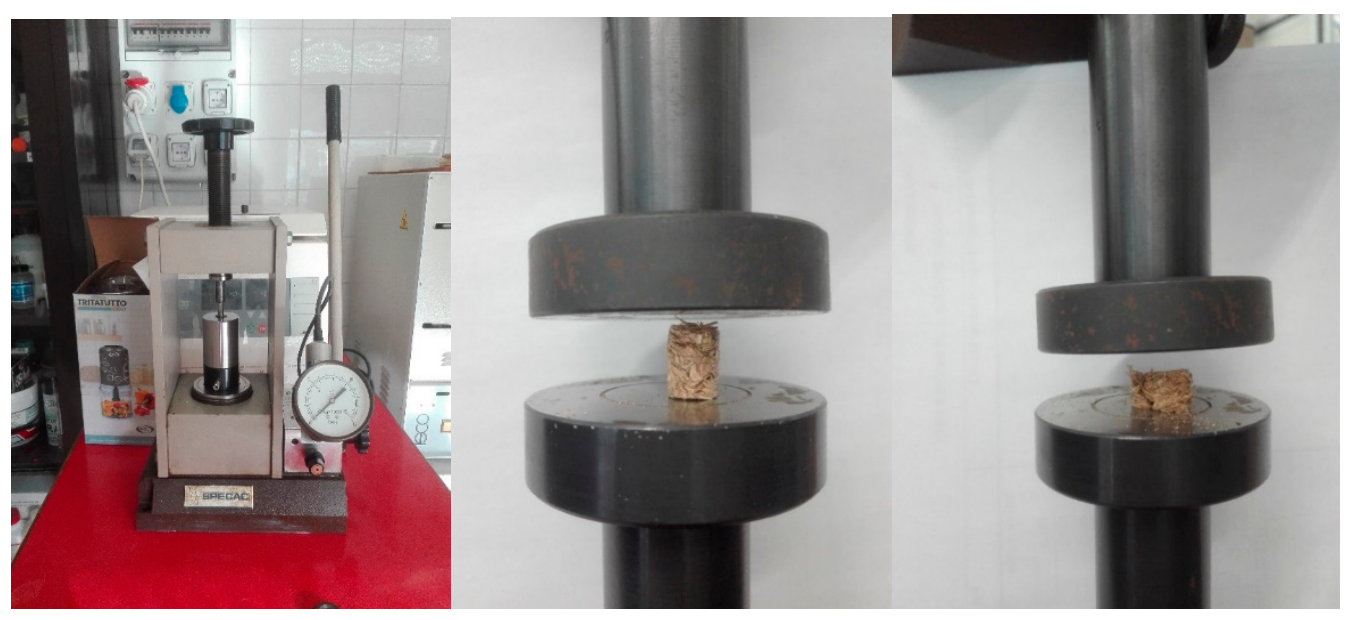

Figure 4. Axial compressive test. 
The axial compressive strength $\left(\sigma_{A C}\right)$ was calculated using:

$$
\sigma_{A C}(M P a)=\frac{4 P}{\pi d^{2}}
$$

where $d$ is the diameter of the pellet $(\mathrm{mm})$ and $P(\mathrm{~N})$ is the failure force.

The elongation at break $(\varepsilon)$ was defined as:

$$
\sigma(\%)=\frac{s}{l} 100
$$

with $s$ the length at break $(\mathrm{mm})$ and $l$ the initial length $(\mathrm{mm})$.

The diametral compressive strength $\left(\sigma_{D C}\right)$ was calculated as:

$$
\sigma_{D C}(M P a)=\frac{2 P}{\pi L d}
$$

where $L$ and $d$ are the length $(\mathrm{mm})$ and diameter $(\mathrm{mm})$ of the pellet and $P(\mathrm{~N})$ is the failure force.

Durability $(D)$ tests were performed on commercial RS and RH pellets to measure their friability and their possibility of breaking apart during processing. With this purpose, an initial quantity of material was weighed $\left(W_{\mathrm{i}}\right)$ and placed in a $0.25 \mathrm{~L}$ recipient. Then, the recipient was tumbled at $50 \mathrm{rpm}$ for $10 \mathrm{~min}$ and sieved afterwards. Finally, the mass of pellets retained on the sieve after tumbling was measured $\left(W_{\mathrm{f}}\right)$. The final weight was compared against its initial value and the difference was expressed as:

$$
D(\%)=\frac{W_{f}}{W_{i}} 100,
$$

\subsubsection{Structural Properties}

Structural analyses were performed on lab-scale pellets using an optical microscope Nikon LV 100 at $50 \times$ in reflection.

All the described analyses were run in triplicate, except where indicated diversely. Averaged results were compared with the standard values established in the non-woody pellet norm (UNE-EN ISO 17225-6) [24]. Table 1 gathers the most representative properties used in this study.

Table 1. Guidelines for specifications of non-woody pellets.

\begin{tabular}{cc}
\hline Parameter & Guidelines \\
\hline Length $(\mathrm{mm})$ & $3.15<$ length $<40$ \\
Diameter $(\mathrm{mm})$ & Die diameter \pm 1 \\
Bulk density $\left(\mathrm{kg} / \mathrm{m}^{3}\right)$ & $>600$ \\
Moisture content $(\mathrm{wt} \%)$ & $<10$ \\
Durability $(\%)$ & $>97.5$ \\
\hline
\end{tabular}

\section{Results}

\subsection{Lab-Scale Pellets}

Palletization is a challenging task when non-conventional wood pellets are produced due to their particular properties in terms of bulk density, geometry, and composition. In order to evaluate the suitability of rice straw to produce adequate pellets, pellets were initially obtained using a single press as described in Section 2.1.

Two different operational conditions were varied: Compression force (from 1 to 10 tons) and percentage (in mass) of added water ( $40 \mathrm{mg}$ and $60 \mathrm{mg}$, corresponding to a $14 \%$ and $20 \%$ wt moisture content, respectively). However, the highest moisture content presented processing difficulties and so only the moisture value of $14 \%$ wt was considered. Physical (dimensions and density), mechanical 
(resistance to axial compression), and structural (distribution of fibers and presence of silica) properties were evaluated.

\subsubsection{Physical Properties}

All the pellets presented a cylindrical shape with around $8 \mathrm{~mm}$ of diameter and $10 \mathrm{~mm}$ length. Samples produced at 6 and 7 tons showed the best performances and were reproduced to obtain a representative amount for their further characterization. Table 2 presents the averaged values of diameter, length, and density of all the repeated samples.

Table 2. Averaged results of physical properties of RS pellets produced at lab conditions.

\begin{tabular}{cccc}
\hline Samples & $\boldsymbol{l}(\mathbf{m m})$ & $\boldsymbol{d}(\mathbf{m m})$ & $\rho_{p}\left(\mathbf{k g} / \mathbf{m}^{\mathbf{3}}\right)$ \\
\hline RS_6 tons & $10.1 \pm 0.3$ & $8.18 \pm 0.02$ & $980 \pm 20$ \\
RS_7 tons & $10.8 \pm 0.6$ & $8.14 \pm 0.03$ & $930 \pm 49$ \\
\hline
\end{tabular}

\subsubsection{Chemical Properties}

Table 3 shows the PA, UA, and HHV of lab-scale RS pellets.

Table 3. Proximate analysis (PA), ultimate analysis (UA), and higher heating value (HHV) of lab-scale RS pellets.

\begin{tabular}{cc}
\hline Physical & RS \\
\hline Proximate analysis (wt \%) & \\
Moisture & 7 \\
Fixed Carbon & 13 \\
Volatile Matter & 71 \\
Ash & 9 \\
Ultimate analysis (wt \%) (ash-free) & \\
Carbon & 46.8 \\
Hydrogen & 5.1 \\
Nitrogen & 0.6 \\
Oxygen & 47.2 \\
Sulfur & 0.3 \\
HHV (MJ/kg) & 15.6 \\
\hline
\end{tabular}

\subsubsection{Mechanical Properties}

Table 4 shows the averaged results of the axial compression tests. Samples obtained at 1, 8, 9, and 10 tons did not provide stable pellets and could not be used for their mechanical characterization.

Table 4. Averaged results of axial compression tests for RS pellets at lab conditions.

\begin{tabular}{ccc}
\hline Samples & $\sigma_{\text {AC }}(\mathbf{M P a})$ & $\varepsilon \mathbf{~} \mathbf{\%})$ \\
\hline RS_2 tons & $56.5 \pm 7.7$ & $0.70 \pm 0.04$ \\
RS_3 tons & $67.7 \pm 2.9$ & $0.72 \pm 0.02$ \\
RS_4 tons & $58.2 \pm 10.4$ & $0.66 \pm 0.04$ \\
RS_5 tons & $61.2 \pm 3.1$ & $0.68 \pm 0.05$ \\
RS_6 tons & $58.4 \pm 7.0$ & $0.69 \pm 0.06$ \\
RS_7 tons & $54.4 \pm 18.9$ & $0.72 \pm 0.15$ \\
\hline
\end{tabular}

\subsubsection{Structural Properties}

Microscopic analyses were performed on lab-scale pellets to evaluate the distribution of fibers in the matrix. Figure 5 shows the fractions $0.3-0.85 \mathrm{~mm}(\mathrm{a})$ and $0.15-0.3 \mathrm{~mm}(\mathrm{~b})$ of the straw powders at the magnification of $50 \times$. Particles appear as straight rods with diameters about $0.1-0.2 \mathrm{~mm}$ (fraction 
0.3-0.85 mm) and as irregular needles with the presence of rectangular pieces in the fraction at lower dimensions (b). In both figures the presence of silica is clearly shown by the light reflection on the surface of the samples.
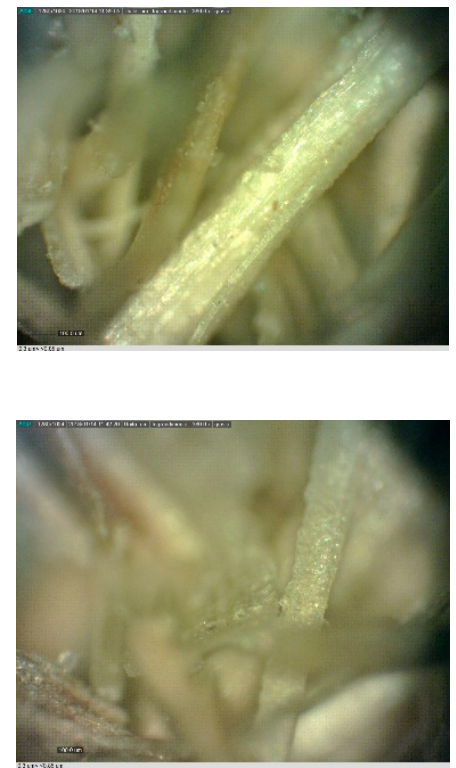

(a)
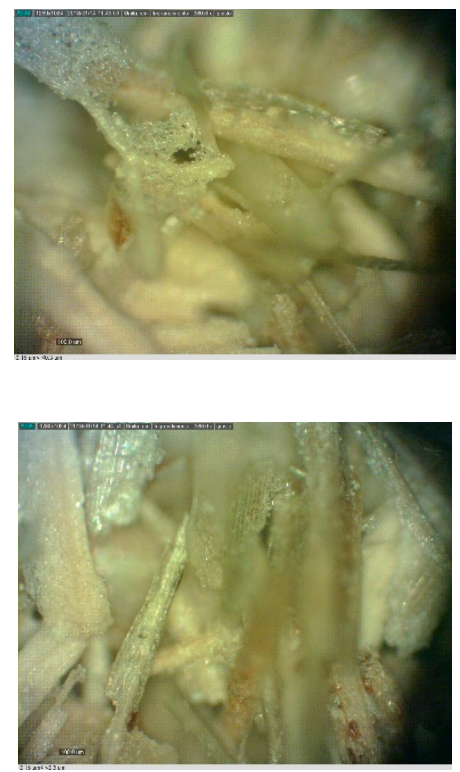

(b)

Figure 5. Fraction $0.3-0.85 \mathrm{~mm} \mathrm{(a)} \mathrm{and} 0.15-0.3 \mathrm{~mm}(\mathbf{b})$ of the straw powders at the magnification of $50 \times$ at optical microscope.

\subsection{Commercial Rice Straw and Rice Husk Pellets}

After the confirmation of the suitability of RS for palletization without the use of any binder, commercial pellets were produced as described in Section 2.2. Afterwards, their main properties were evaluated.

\subsubsection{Physical Properties}

The size of pellets greatly influences feeding and combustion processes. In general, shorter pellets promote a more continuous inflow, as solid obstructions are more unlikely to occur. Longer pellets can be more easily broken during storage, handling, and processing but can also provoke bridging problems. Thinner pellets allow a more uniform and efficient combustion rate.

As shown in Table 1, the norm [24] sets the diameter limit at die diameter $\pm 1 \mathrm{~mm}$ and a length range between 3.15 and $40 \mathrm{~mm}$. Table 5 shows the dimensions of RS and RH pellets. Die diameter was $6 \mathrm{~mm}$ in all cases.

Table 5. Averaged dimensions of RS and rice husk (RH) pellets.

\begin{tabular}{ccc}
\hline Dimensions & RS & RH \\
\hline$L(\mathrm{~mm})$ & $17.7 \pm 1.0$ & $8.5 \pm 2.5$ \\
$d(\mathrm{~mm})$ & $6.3 \pm 0.1$ & $6.4 \pm 0.1$ \\
$L / d$ & $2.8 \pm 0.1$ & $1.3 \pm 0.1$ \\
\hline
\end{tabular}

Visual observations of pellets showed differences in size (RS-Figure 6a; RH-Figure 6b). RH pellets showed lower length values than RS pellets and a more fragile behavior during its manipulation. 


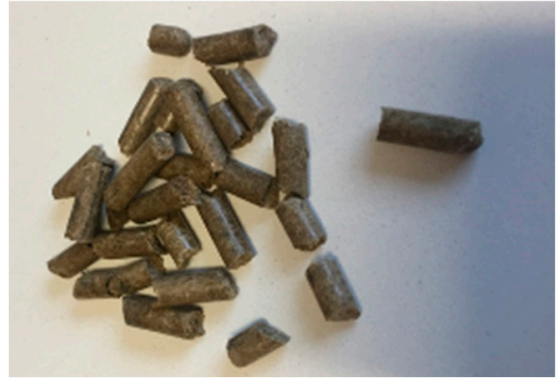

(a)

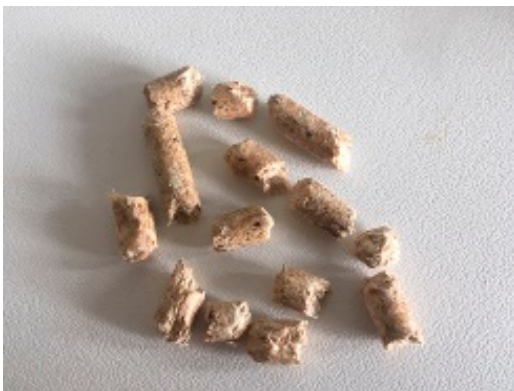

(b)

Figure 6. RS (a) and RH (b) pellets.

In any case, the dimensions of both pellets were within the range established by the norm. A slight increase in the diameter indicated a pellet expansion after its release from the die, an effect also shown in other materials [25]. RH pellets had the lowest $L / d$ ratio and both materials presented values similar to other biomass pellets (e.g. black poplar $=3.64$; holm oaks $=2.18$; and leaves of olive trees $=1.76$ [12]).

Bulk density $\left(\rho_{b}\right)$ greatly influences storage and transport processes as well as combustion efficiencies. Particle density $\left(\rho_{p}\right)$ might affect combustion efficiency as highly packed materials might prevent oxygen to access within the particles. The norm [24] suggests a value $\rho_{b}>600 \mathrm{~kg} / \mathrm{m}^{3}$. No guidelines are established for $\rho_{p}$ with a recommended value of $1200 \mathrm{~kg} / \mathrm{m}^{3}$.

Porosity $\left(\varepsilon_{0}\right)$ influences heat and mass transfer phenomena and thus the combustion parameters such as burning rate, conversion efficiency, and emissions [26]. Table 6 shows the densities and porosities of RS and RH pellets.

Table 6. Averaged density and porosity of RS and RH pellets.

\begin{tabular}{ccc}
\hline Physical & RS & RH \\
\hline$\rho_{b}\left(\mathrm{~kg} / \mathrm{m}^{3}\right)$ & $606 \pm 20$ & $505 \pm 15$ \\
$\rho_{p}\left(\mathrm{~kg} / \mathrm{m}^{3}\right)$ & $1305 \pm 34$ & $1112 \pm 38$ \\
$\varepsilon_{0}(-)$ & 0.536 & 0.544 \\
\hline
\end{tabular}

RS was just within the range established by the norm and above the recommended particle density value. On the contrary, $\mathrm{RH}$ fell out of the optimal ranges presenting lower values than those recommended in all cases. These results are in accordance with other studies in which RS pellets presented higher density values than RH pellets [11].

In summary and regarding physical properties of pellets, RS was considered as a suitable material according to the standards whereas $\mathrm{RH}$ presented length values close to the minimum permitted and a density out of the recommended range.

\subsubsection{Chemical Properties}

Chemical energy is stored in biomass in two forms: Volatiles and fixed carbon. VM is defined as the released gas by heating and FC is the mass remaining after this release, excluding the ash and moisture contents (MC).

The content of volatiles also influences the ignition temperature which is the temperature above which combustion reactions become self-sustaining. In general, the ignition temperature is lower for higher VM contents.

The composition of pellets described by their PA was carried out using a muffle furnace following the standards [20-22]. The energy developed during the combustion of RS and RH pellets was evaluated through the HHV. Table 7 lists the PA, UA, and HHV (calculated by Equation 2) of RS and RH pellets. 
Table 7. PA, UA, and HHV of RS and RH pellets.

\begin{tabular}{ccc}
\hline Physical & RS & RH \\
\hline \multicolumn{3}{c}{ Proximate analysis (wt \%) } \\
\hline Moisture & 15 & 17 \\
Fixed Carbon & 11 & 11 \\
Volatile Matter & 60 & 63 \\
Ash & 14 & 9 \\
\hline Ultimate analysis (wt \%)—ash-free \\
\hline Carbon & 43.9 & 52.1 \\
Hydrogen & 4.7 & 6.2 \\
Nitrogen & 0.6 & 2.2 \\
Oxygen & 50.5 & 39.3 \\
Sulfur & 0.3 & 0.2 \\
\hline HHV $(\mathrm{MJ} / \mathrm{kg})$ & 13.2 & 13.8 \\
\hline
\end{tabular}

Similar compositions were found for both feedstocks. A slightly higher value of volatile matter for RH pellets led to a slightly higher heating value. The ash content, main objective of LIFE LIBERNITRATE, was higher in RS pellets identifying them as a better choice in terms of material efficiency. Comparing the composition before and after densification, slightly higher volatile contents were found for pellets with respect to raw straw $\left(\mathrm{VM}_{\text {raw }}=57.5 \%\right.$ [27]). They also presented higher $\mathrm{HHV}\left(\mathrm{HHV}_{\text {raw }}=11.6 \mathrm{MJ} / \mathrm{kg}\right.$ [27]) which indicated an increased energy emission during the combustion due to densification. On the contrary, the ash content slightly decreased with respect to raw materials $\left(\mathrm{A}_{\text {raw }}=18.8 \%\right.$ [27]). This suggested that a higher quantity of pellets will need to be processed in order to achieve the same quantitative efficiencies. HHV values were found to be lower than commercial wood pellets for both feedstocks $\left(\mathrm{HHV}_{\text {wood }}=19.5 \mathrm{MJ} / \mathrm{kg}\right.$ [28]). An increase in these values could be achieved by mixing them with other available residues $\left(\mathrm{HHV}_{\text {persimmon stems }}=17.3 \mathrm{MJ} / \mathrm{kg}\right.$ [29] or $\mathrm{HHV}_{\text {appletrees }}$ $=17.2 \mathrm{MJ} / \mathrm{kg}$ [30]). That way, the increase in the quality of the final pellet would permit using these residues with low calorific values in energy recovery processes. Sulfur and nitrogen contents remained in a very low percentage (below $0.3 \% \mathrm{wt}$ and $2.5 \% \mathrm{wt}$, respectively). This low sulfur and nitrogen content results in low $\mathrm{NO}_{\mathrm{X}}$ and $\mathrm{SOx}$ emissions and contributing to minimize environmental damage.

\subsubsection{Mechanical Properties}

Axial and diametral compressive tests were performed on RS and RH samples at the Laboratorio di Ingegneria dei Materiali (DICCA, UNIGE). Ten specimens were tested except for the RH in the axial compression test where only one specimen was tested due to its extreme fragility. The load at fracture was obtained from the stress-strain curve (as shown in Figure 7a for RS and Figure $7 \mathrm{~b}$ for RH) from which the main mechanical properties were calculated.

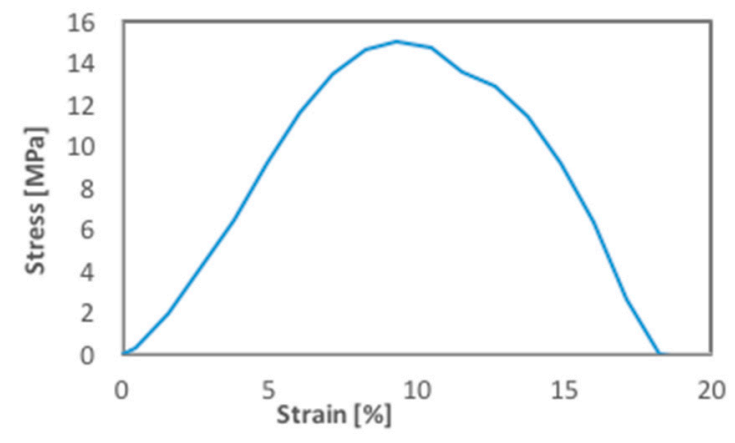

(a)

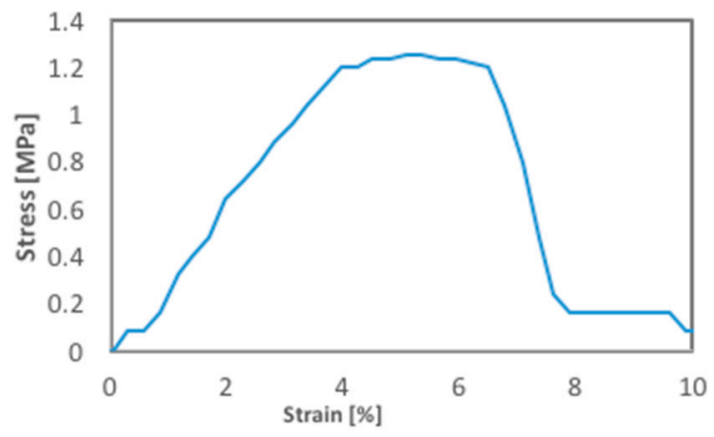

(b)

Figure 7. Axial compressive stress-strain curves for RS pellets (a) and RH pellets (b). 
The mean values for axial compression strength $\left(\sigma_{\mathrm{AC}}, \mathrm{MPa}\right)$, deformation at break $(\varepsilon, \%)$, and diametral compression strength $\left(\sigma_{\mathrm{DC}}, \mathrm{MPa}\right)$ for $\mathrm{RS}$ and $\mathrm{RH}$ pellets are listed in Table 8 . The high values of standard deviation were attributed to the heterogeneous nature of the biomass samples.

Table 8. Averaged results of axial and diametral compression tests for RS and RH pellets.

\begin{tabular}{ccc}
\hline & RS & RH \\
\hline$\sigma_{\mathrm{AC}}(\mathrm{MPa})$ & $11.0 \pm 2.0$ & 1.17 \\
$\varepsilon(\%)$ & $7.5 \pm 3.2$ & 8.12 \\
$\sigma_{D C}(\mathrm{MPa})$ & $7.8 \pm 2.5$ & $4.26 \pm 2.57$ \\
\hline
\end{tabular}

RS pellets presented higher mechanical resistance in both directions in comparison to RH pellets. This fact indicated a stronger bonding as a result of a more efficient densification process. Mechanical strength varies significantly with direction of load and feedstock. Compressive stress was higher in the axial orientation for RS pellets whereas RH presented higher values in the diametral orientation. Because the diametral compression is an indirect measure of the tensile properties, a higher value of $\sigma_{\mathrm{DC}}$ with respect to $\sigma_{\mathrm{AC}}$ is probably due to the prevalent orientation of the fibers along the longitudinal direction of cylinder. Mechanical strength of pellets is highly related to their physical and chemical properties. The higher moisture content, lower density, and lower length of pellets resulted in lower mechanical strength values. This might be attributed to the lower adhesion forces between particles, in accordance with other works [11]. Compression strength values were consistent with other pellet values like eucalyptus pellets $\left(\sigma_{A C}=5.5 \mathrm{MPa} ; \sigma_{D C}=9.9 \mathrm{MPa}\right)$, wood pellets $\left(\sigma_{A C}=4.1 \mathrm{MPa} ; \sigma_{D C}=9.5 \mathrm{MPa}\right)$, or sunflower pellets $\left(\sigma_{A C}=7.5 \mathrm{MPa} ; \sigma_{D C}=6.5 \mathrm{MPa}\right)$ [31].

Following these results, it is concluded that RS pellets present an adequate mechanical strength whereas RH pellets were too fragile and not resistant to mechanical forces. This fact could lead to increased dust emissions and higher risks of fire and explosion and so they were not considered as a valid feedstock.

Durability is one of the most important factors defining the quality of pellets. Low values can lead to problems such as blocking in the feeding system, dust emissions, and higher risk of explosions during handling and storage [14]. The norm [24] recommends a value over $97.5 \%$. The calculated durability values of RS and RH pellets were $99.8 \%$ and $91.8 \%$, respectively. Durability of RS pellets was higher than RH pellets probably due to their different physical characteristics. RS is more flexible, and particles can be in closer contact than RH particles during palletization favoring a correct densification. The durability of RS pellets was well over the limit value according to the standards. On the contrary, the durability of RH pellets was slightly lower than the recommended value and so failed to accomplish the established requirements.

Overall, commercial RS pellets showed adequate properties according to the quality standards. However, the low HHV values suggested that mixing with other materials could improve their calorific value. On the contrary, commercial RH pellets fell out of the standards in several tests such as recommended size or durability. Different operational conditions during pellet production or mixing of rice husk with other biomass could permit using these residues for pellet production to take advantage of the discussed densification processes.

In summary, an adequate densification of biomass could reduce costs and operational difficulties with handling, transportation, storage, and utilization of low bulk density materials. However, the feedstock and the operational parameters for pellets production need to be carefully examined to determine the technical suitability of the produced materials and potential required improvements. In addition to these technical considerations, further economic and environmental studies will be performed in the context of LIFE LIBERNITRATE to evaluate the global impact on the project. 


\section{Conclusions}

Pellets from residues from rice harvest (i.e., straw and husk) were produced and their main properties were evaluated. Rice straw pellets were initially produced at lab scale at varying operational conditions (i.e., load compression and wt $\%$ of feeding moisture content) to evaluate their suitability for palletization without the use of binders. Afterwards, pellets from rice straw and husk pellets were commercially produced without the use of a binder.

All the samples were characterized in terms of their main physical (density, dimension, porosity), physico-chemical (proximate and ultimate analysis, higher heating value), and structural properties. In addition, axial and diametral compression tests and durability tests were used to assess their mechanical performance. All the analyzed properties were compared with the established quality standards for non-woody pellets.

In summary, rice straw pellets presented suitable properties for their use as pelletized fuels in the context of the LIFE LIBERNITRATE project. Rice husk pellets fell out of the standards in several tests such as recommended size or durability and their pre-treatment might be necessary for their use as fuels.

Author Contributions: Conceptualization, methodology, writing draft, formal analysis C.M. and A.L. writing-review and editing, B.B., R.B. supervision, funding acquisition, E.A. All authors have read and agreed to the published version of the manuscript.

Funding: This work was funded through the LIFE LIBERNITRATE project (LIFE16 ENV/ES/000419).

Acknowledgments: Beatrice Ghinello, Matteo Toscanini and Alice Gabuti are acknowledged in the framework of their thesis work.

Conflicts of Interest: The authors declare no conflict of interest.

\section{References}

1. Food and Agriculture Organization of the United Nations. World Agriculture: Towards 2015-2030; Summary Report; Earthscan Publications Ltd: London, UK, 2002.

2. Moliner, C.; Badia, J.D.; Bosio, B.; Arato, E.; Kittikorn, T.; Strömberg, E.; Ribes-Greus, A. Thermal and thermo-oxidative stability and kinetics of decomposition of PHBV/sisal composites. Chem. Eng. Commun. 2018, 205, 226-237. [CrossRef]

3. Moliner, C.; Teruel-Juanes, R.; Primaz, C.; Badia, J.; Bosio, B.; Campíns-Falcó, P.; Morán, J. Reduction of Nitrates in Waste Water through the Valorization of Rice Straw: LiFE libernitrate Project. Sustainability 2018, 10, 3007. [CrossRef]

4. Moliner, C.; Curti, M.; Bosio, B.; Arato, E.; Rovero, G. Experimental Tests with Rice Straw on a Conical Square-Based Spouted Bed Reactor. Int. J. Chem. React. Eng. 2018, 13, 351-358. [CrossRef]

5. Mansaray, K.G.; Ghaly, A.E. Physical and Thermochemical Properties of Rice Husk. Energy Sources 1997, 19, 989-1004. [CrossRef]

6. Obernberger, I.; Thek, G. Physical characterisation and chemical composition of densified biomass fuels with regard to their combustion behaviour. Biomass Bioenergy 2004, 27, 653-669. [CrossRef]

7. Kaliyan, N.; Morey, R.V. Factors affecting strength and durability of densified biomass products. Biomass Bioenergy 2009, 33, 337-359. [CrossRef]

8. Larsson, S.H.; Thyrel, M.; Geladi, P.; Lestander, T.A. High quality biofuel pellet production from pre-compacted low density raw materials. Bioresour. Technol. 2008, 99, 7176-7182. [CrossRef] [PubMed]

9. Serrano, C.; Monedero, E.; Lapuerta, M.; Portero, H. Effect of moisture content, particle size and pine addition on quality parameters of barley straw pellets. Fuel Process. Technol. 2011, 92, 699-706. [CrossRef]

10. Ewida, K.T.; El-Salmawy, H.; Atta, N.N.; Mahmoud, M.M. A sustainable approach to the recycling of rice straw through pelletization and controlled burning. Clean Technol. Environ. Policy 2006, 8, 188-197. [CrossRef]

11. Yang, I.; Kim, S.H.; Sagong, M.; Han, G.S. Fuel characteristics of agropellets fabricated with rice straw and husk. Korean J. Chem. Eng. 2016, 33, 851-857. [CrossRef]

12. Zamorano, M.; Popov, V.; Rodríguez, M.L.; García-Maraver, A. A comparative study of quality properties of pelletized agricultural and forestry lopping residues. Renew. Energy 2011, 36, 3133-3140. [CrossRef] 
13. Osman, A.I. Mass spectrometry study of lignocellulosic biomass combustion and pyrolysis with NOx removal. Renew. Energy 2020, 146, 484-496. [CrossRef]

14. Temmerman, M.; Rabier, F.; Jensen, P.D.; Hartmann, H.; Böhm, T. Comparative study of durability test methods for pellets and briquettes. Biomass Bioenergy 2006, 30, 964-972. [CrossRef]

15. ISO E. Solid Biofuels-Fuel Specifications and Classes-Part 1: General Requirements. 2014. Available online: https://www.iso.org/standard/59456.html (accessed on 18 January 2020).

16. Novapellet [online]. Available online: http://novapellet.it/inglese/index.htm (accessed on 3 May 2019).

17. Moliner, C.; Lagazzo, A.; Bosio, B.; Botter, R.; Arato, E. Production and characterisation of pellets from rice straw and rice husk. In Proceedings of the European Biomass Conference and Exhibition, Lisbon, Portugal, 27-30 May 2019; pp. 1023-1028.

18. UNE-EN 15150. Solid Biofuels. Determination of Particle Density. 2012. Available online: https://www.une. org/encuentra-tu-norma/busca-tu-norma/norma/?Tipo=N\&c=N0049721 (accessed on 18 January 2020).

19. UNE-EN 15103. Solid Biofuels. Determination of Bulk Density. 2010. Available online: https://www.une.org/ encuentra-tu-norma/busca-tu-norma/norma/?c=N0046378 (accessed on 18 January 2020).

20. UNE-EN 14774-3. Solid Biofuels—Determination of Moisture Content—Oven Dry Method—Part 3: Moisture in General Analysis Sample. 2010. Available online: https:/www.une.org/encuentra-tu-norma/busca-tunorma/norma/?c=N0045728 (accessed on 18 January 2020).

21. DIN-EN 15148. Solid Biofuels—Determination of Volatile Content-Oven Dry Method—Part 5: Volatiles in General Analysis 2010. Available online: https://infostore.saiglobal.com/en-us/Standards/DIN-EN-151482010-448122_SAIG_DIN_DIN_1010653/ (accessed on 18 January 2020).

22. DIN-EN 14775. Solid Biofuels-Determination of Ash Content-Oven Dry Method-Part 4: Ash in General Analysis 2010. Available online: https://www.beuth.de/en/standard/din-en-14775/165912452 (accessed on 18 January 2020).

23. Parikh, J.; Channiwala, S.A.; Ghosal, G.K. A correlation for calculating HHV from proximate analysis of solid fuels. Fuel 2005, 84, 487-494. [CrossRef]

24. UNE-EN ISO 17225-6. Solid Biofuels, Fuel Specifications and Classes. Part 6: Graded Non-Woody Pellets. 2014. Available online: https://www.iso.org/obp/ui/\#iso:std:iso:17225:-6:ed-1:v1:en (accessed on 18 January 2020).

25. Said, N.; García-Maraver, A.; Zamorano, M. Influence of densification parameters on quality properties of rice straw pellets. Fuel Process. Technol. 2015, 138, 56-64. [CrossRef]

26. Igathinathane, C.; Tumuluru, J.S.; Sokhansanj, S.; Bi, X.; Lim, C.J.; Melin, S.; Mohammad, E. Simple and inexpensive method of wood pellets macro-porosity measurement. Bioresour. Technol. 2010, 101, 6528-6537. [CrossRef] [PubMed]

27. Moliner, C.; Bosio, B.; Arato, E.; Ribes, A. Thermal and thermo-oxidative characterisation of rice straw for its use in energy valorisation processes. Fuel 2016, 180, 71-79. [CrossRef]

28. Bove, D.; Moliner, C.; Curti, M.; Baratieri, M.; Bosio, B.; Rovero, G.; Arato, E. Preliminary tests for the thermo-chemical conversion of biomass in a spouted bed pilot plant. Can. J. Chem. Eng. 2018, 97, 57-66. [CrossRef]

29. Moliner, C.; Aguilar, K.; Bosio, B.; Arato, E.; Ribes, A. Thermo-oxidative characterisation of the residues from persimmon harvest for its use in energy recovery processes. Fuel Process. Technol. 2016, 152, 421-429. [CrossRef]

30. Bove, D. Experimental studies on the gasification of the residues from prune of apple trees with a spouted bed reactor. In Proceedings of the European Biomass Conference and Exhibition, Amsterdam, The Netherlands, 6-9 June 2016; pp. 858-862.

31. Williams, O.; Taylor, S.; Lester, E.; Kingman, S.; Giddings, D.; Eastwick, C. Applicability of Mechanical Tests for Biomass Pellet Characterisation for Bioenergy Applications. Materials 2018, 11, 1329. [CrossRef] [PubMed]

(C) 2020 by the authors. Licensee MDPI, Basel, Switzerland. This article is an open access article distributed under the terms and conditions of the Creative Commons Attribution (CC BY) license (http://creativecommons.org/licenses/by/4.0/). 